\title{
Desempenho, balanço e retenção de nutrientes e biometria dos órgãos digestivos de frangos de corte alimentados com diferentes níveis de proteína na ração pré-inicial
}

\author{
José Henrique Stringhini ${ }^{1,3}$, Michelle Lobo Andrade ${ }^{2}$, Leonardo Andrade 2,4 , Suzany \\ Aparecida Gomes Xavier ${ }^{2,3}$, Marcos Barcellos Café1, Nadja Susana Mogyca Leandro1

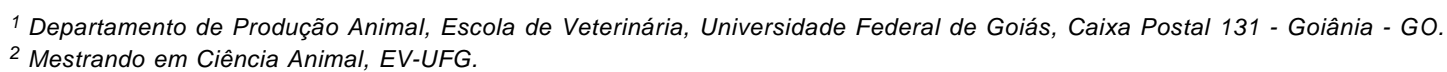

RESUMO - Dois experimentos foram conduzidos para avaliar o desempenho, o balanço e a retenção de MS, EE e PB e os parâmetros biométricos do trato gastrintestinal de frangos de corte recebendo diferentes níveis de proteína na ração préinicial (1 a 7 dias). No experimento 1, 560 pintos Avian Farms foram distribuídos em baterias segundo um delineamento inteiramente casualizado, em esquema fatorial 5 x 2 (cinco níveis de proteína, 18, 20, 22, 24 e 26\%, e dois sexos), com dez tratamentos, cada um com quatro repetições de 14 aves. No experimento 2, 1.860 pintos machos e fêmeas Ross foram distribuídos em boxes de 2,0 x 2,5 m, em um delineamento em blocos casualizados, com cinco tratamentos (níveis de proteína, 18, 20, 22, 24 e 26\%), cada um com seis repetições de 62 aves. No experimento 1, os níveis crescentes de PB da dieta não afetaram significativamente os dados de desempenho, mas o balanço e a quantidade retida do EE promoveram efeito linear positivo. O balanço de proteína não foi afetado, mas a retenção de proteína apresentou efeito linear positivo. A biometria dos órgãos não foi significativamente influenciada aos quatro dias. Nos períodos seguintes, os níveis crescentes de proteína afetaram positivamente o peso relativo do pâncreas. No experimento 2, observou-se, com base nos resultados de desempenho, que os mais altos níveis de proteína na ração pré-inicial atenderam às necessidades nutricionais das aves.

Palavras-chave: balanço nutricional, desempenho, dietas, órgãos digestivos

\section{Performance, nutrient balance and retention and biometrical measures of digestive organs of broilers fed different dietary protein levels in the pre- starter period}

\begin{abstract}
AB STRACT - Two trials were carried out to evaluate performance, balance and retention of EE, DM and CP and biometrical measures of digestive organs of broiler chicks fed different dietary CP levels in the pre-starter period ( 1 - $7 \mathrm{~d})$. In the first experiment, 560 one-day-old Avian Farms chicks were allotted to a complete randomized design with ten treatments, with a $5 \times 2$ (protein levels: $18,20,22,24$, and $26 \%$ x sex) factorial arrangement and four replicates of 14 birds each. In the second experiment, 1,860 one-day-old Ross chicks were assigned to $2.0 \times 2.5 \mathrm{~m}$ experimental pens. This experiment was analyzed as a complete randomized design, with five treatments (protein level - 18, 20, 22, 24, and 26\%) and six replications of 62 birds each. In the first experiment, increasing dietary CP levels in the pre-starter period did not affect performance, but balance and retention of EE had linear and positive effects according to the treatments. No treatment effect on protein balance was observed, but protein retention showed linear and positive effect. No significant differences were observed for biometrical measures on $4^{\text {th }}$ fday of experiment, but increasing CP levels improved the pancreas relative weight. In the experiment 2 , it was possible to conclude that the higher protein levels are indicated for better results in performance.
\end{abstract}

Key Words: digestive organs, nutritional balance, performance, pre-starter

\section{Introdução}

As informações sobre necessidades nutricionais para a fase pré-inicial indicam valores diferentes dos observados para as fases inicial, de crescimento e final. Nos primei- ros dias de vida, as características anatomofisiológicas do aparelho digestivo, que gera dificuldades em digerir e absorver certos nutrientes, o crescimento acelerado e a grande dificuldade de termorregulação justificam o uso de dieta específica nessa fase (Penz \& Vieira, 1998). 
Vários fatores influenciam o crescimento no período pós-eclosão, como a quantidade de resíduos do saco vitelínico, a ingestão de ração e de água, os níveis de enzimas pancreáticas e intestinais, a área de superfície intestinal e a digestibilidade global de nutrientes (Moran Jr., 1985; Dibner, 1996). A maturidade de digestão e de absorção de nutrientes ocorre quando os enterócitos das criptas gradualmente substituem os enterócitos formados durante a fase embrionária (Baranyiová \& Holman, 1976; Moran Jr., 1985; Uni et al.; 1999; Sklan, 2001). Além dessas características, o aporte nutritivo do saco vitelínico parece não ser suficiente para o desenvolvimento esperado de linhagens selecionadas para rápido crescimento (Uni et al., 1998; Gonzales et al., 2000; Sklan \& Noy, 2000; Gonzáles \& Saldanha, 2001).

Deschepper \& De Groote (1995), utilizando dez diferentes dietas, considerando níveis de proteína e de aminoácidos essenciais e não-essenciais, verificaram que a redução dos níveis de proteína ( 21 e $20 \%$ para as rações de 1 a 21 dias e de 22 a 42 dias, respectivamente) com a suplementação de aminoácidos essenciais e não-essenciais permitiu melhores valores de desempenho e utilização mais eficiente da proteína ingerida, como resultado da maior retenção de nitrogênio.

Menores valores para conversão alimentar têm sido observados à medida que os níveis de proteína da dieta são aumentados (Holsheimer \& Janssen, 1991; Parr \& Summers, 1991; Ziggers, 2002).

Stringhini (1998) verificou que os valores de 22 a $24 \%$ de proteína na fase pré-inicial proporcionaram melhores desempenhos de frangos de corte, o que sugere maior necessidade de proteína neste período.

Freitas et al. (1999), ao trabalharem com inclusão de óleo de soja na ração pré-inicial, constataram maior digestibilidade aparente de EE, com alto valor na primeira semana, acompanhado de redução na segunda semana e novo aumento na terceira semana. A digestibilidade da PB manteve-se em torno de $70 \%$ durante a primeira semana, diminuiu para menos de $60 \%$ na segunda semana e voltou a aumentar aos 21 dias de idade.

Em contrapartida, Maiorka (2002) avaliou o uso de diferentes níveis de energia ou de óleo de soja na dieta préinicial de frangos de corte e concluiu que altos níveis de energia provenientes de lipídios não melhoraram o desempenho das aves. Rocha et al. (2003) testaram a interação de três níveis de PB (20, 23 e 26\%) e de dois níveis de energia metabolizável $(2.850$ e $3.000 \mathrm{kcal} / \mathrm{kg}$ ) e verificaram diferenças no consumo de ração e na conversão alimentar de 1 a 7 dias e no consumo de ração de 1a 21 dias, indicando que os maiores níveis de proteína e os menores de EM foram os mais adequados para esta fase.
O objetivo neste experimento foi avaliar o desempenho, o balanço e a retenção de MS, EE e PB e a biometria dos órgãos digestivos de frangos de corte recebendo diferentes níveis de proteína na ração pré-inicial (1 a 7 dias).

\section{Material e Métodos}

Foram conduzidos dois experimentos, um no Aviário Experimental da Escola de Veterinária da Universidade Federal de Goiás, em Goiânia - GO (experimento 1) e outro no Aviário Experimental da Fazenda Roque, em Itaberaí, Goiás (experimento 2).

No experimento 1, avaliaram-se o desempenho, o balanço e a retenção de nutrientes e a biometria de órgãos digestivos de frangos alimentados com diferentes níveis de proteína na fase pré-inicial. Foram utilizados 560 pintos de corte Avian Farms, sexados e vacinados contra Marek no incubatório, distribuídos em delineamento experimental inteiramente casualizado, em esquema fatorial 5 x 2 (cinco níveis de proteína, 18, 20, 22, 24 e 26\%, e dois sexos), constituindo dez tratamentos, cada um com quatro repetições de 14 aves. As aves foram mantidas em oito baterias de aço galvanizado, aquecidas e equipadas com comedouros e bebedouros do tipo linear, bandejas metálicas para a retirada das excretas e uma lâmpada incandescente de $60 \mathrm{~W}$ para aquecimento. Cada bateria continha cinco andares com divisões de $0,33 \times 0,50 \mathrm{~m}$, totalizando 40 unidades experimentais. Água e ração foram disponibilizadas à vontade.

As rações pré-iniciais fornecidas no período de 1 a 7 dias de idade foram formuladas à base de milho e farelo de soja e continham $2.850 \mathrm{kcal}$ de EM/kg e 18, 20, 22, 24 e $26 \%$ de PB (Tabela 1). Em todos os tratamentos da fase de 8 a 21 dias, foi fornecida uma ração inicial única (Tabela 1), com $21,1 \%$ de PB e $2.900 \mathrm{kcal} / \mathrm{kg}$ de EM, de acordo com a composição de alimentos e as exigências nutricionais preconizadas por Rostagno et al. (2000).

Foram medidos os pesos das aves e das rações no 1 o, 4 으, 7으, 10으, 14으, 18으 e 21으 dias de idade. Calculou-se ainda a mortalidade das aves, por meio do registro da data de ocorrência e do peso das aves ao longo do período experimental.

O ensaio de metabolismo foi realizado durante a primeira semana, utilizando-se o método de coleta total de excretas (Albino et al., 1992; Café, et al., 2000); os três primeiros dias foram destinados à adaptação das aves às rações experimentais e o período entre o $4 \underline{\mathrm{o}}$ e o $7 \underline{\mathrm{o}}$ dia à coleta de excretas. As excretas foram retiradas duas vezes ao dia e acondicionadas em sacos plásticos identificados para determinação dos teores de MS (a 55 e $105^{\circ} \mathrm{C}$ ), nitrogênio total e EE. Foram compostas amostras das rações experimentais para estimativa dos teores de 
Tabela 1 - Composição e níveis nutricionais das rações pré-inicial e inicial (experimentos 1 e 2) Table 1 - Composition and nutritional levels of the pre-starter and starter diets (experiments 1 and 2)

\begin{tabular}{|c|c|c|c|c|c|c|}
\hline \multirow[t]{2}{*}{$\begin{array}{l}\text { Ingrediente } \\
\text { Ingredient }\end{array}$} & \multicolumn{5}{|c|}{$\begin{array}{c}\text { Nível de } \mathrm{PB} \text { na ração pré-inicial ( } 1 \text { a } 7 \text { dias) } \\
\text { CP levels in the pre-starter diet (1 to } 7 \text { days) }\end{array}$} & \multirow{2}{*}{$\begin{array}{l}\text { Inicial } \\
\text { Starter } \\
(8-21 \mathrm{~d})\end{array}$} \\
\hline & 18 & 20 & 22 & 24 & 26 & \\
\hline Farelo de soja (Soybean meal) & 25,8 & 31,4 & 37,2 & 42,5 & 44,4 & 37,1 \\
\hline Fosfato bicálcico (Dicalcium phosphate) & 1,96 & 1,93 & 1,89 & 1,8 & 1,83 & 1,97 \\
\hline Calcário calcítico (Limestone) & 1,12 & 1,09 & 1,06 & 1,03 & 0,996 & 0,95 \\
\hline L-treonina (L-threonine) & 0,148 & 0,058 & - & - & - & \\
\hline Sal comum (Salt) & 0,472 & 0,46 & 0,449 & 0,439 & 0,43 & 0,27 \\
\hline Supl. vitamínico (Vitamin supplement $)^{1}$ & 0,40 & 0,40 & 0,40 & 0,40 & 0,40 & 0,40 \\
\hline Supl. mineral (Mineral supplement $)^{2}$ & 0,05 & 0,05 & 0,05 & 0,05 & 0,05 & \\
\hline Óleo vegetal (Vegetable oil) & 1,00 & 1,00 & 1,00 & 1,439 & 2,58 & 0,476 \\
\hline Inerte $(\text { Inert })^{3}$ & 5,825 & 3,987 & 2,077 & 1,00 & 1,00 & - \\
\hline $\mathrm{PB}(\%)(C P, \%)$ & 18,0 & 20,0 & 22,1 & 24,0 & 26,0 & 21,1 \\
\hline EMAn $(\mathrm{kcal} / \mathrm{kg})($ AMEn, kcal/kg) & 2.850 & 2.850 & 2.850 & 2.850 & 2.850 & 2.900 \\
\hline Ác. linoleico (\%) (Linoleic acid, \%) & 1,782 & 1,743 & 1,703 & 1,864 & 2,380 & 2,696 \\
\hline Lisina $(\%)($ Lysine, \%) & 1,067 & 1,307 & 1,307 & 1,350 & 1,499 & 1,200 \\
\hline Met + Cis $(\%)($ Met + Cis, \%) & 0,926 & 0,926 & 0,926 & 0,926 & 0,926 & 0,794 \\
\hline Treonina (\%) (Threonine, \%) & 0,823 & 0,823 & 0,859 & 0,939 & 1,018 & 0,860 \\
\hline Triptofano (\%) (Thryptophan, \%) & 0,228 & 0,264 & 0,301 & 0,334 & 0,368 & 0,296 \\
\hline Cálcio (\%) (Calcium, \%) & 0,988 & 0,988 & 0,988 & 0,988 & 0,988 & 0,966 \\
\hline P disponível (\%) (Available P, \%) & 0,466 & 0,466 & 0,466 & 0,466 & 0,466 & 0,484 \\
\hline Sódio (\%) (Sodium, \%) & 0,224 & 0,224 & 0,224 & 0,224 & 0,224 & 0,154 \\
\hline
\end{tabular}

MS (a $105^{\circ} \mathrm{C}$ ), nitrogênio total e EE. Foram calculados ainda os balanços nutricionais, como proposto por Matterson et al. (1965), e aretenção de MS, nitrogênio e EE, determinada pela quantidade ingerida subtraída da quantidade excretada dividida pelo ganho de peso. Os valores de retenção de nutrientes propostos foram determinados conforme descrito por Noy \& Sklan (2002).

No 4으, 7으, 10으 e 14을 dias de idade, quatro aves por tratamento foram identificadas e transportadas ao Laboratório de Doenças de Aves do Departamento de Medicina Veterinária da Escola de Veterinária da UFG, onde foram submetidas a jejum de aproximadamente 5 horas, sendo pesadas e posteriormente sacrificadas por deslocamento cervical. Foram avaliados o comprimento do TGI, o peso do esôfago + papo, do pró-ventrículo + moela, do pâncreas, do intestino delgado, do intestino grosso e do fígado + vesícula biliar. Todos os pesos obtidos foram utilizados no cálculo do peso relativo de cada órgão, pela fórmula: peso relativo do órgão $=($ peso do órgão / peso vivo $)$ x 100 .
Os dados foram analisados utilizando-se o programa SAEG (UFV, 1998). Realizou-se análise de variância e, para os teores de $\mathrm{PB}$, analisaram-se os dados por regressão polinomial. Os valores obtidos para sexo, no entanto, foram analisados pelo teste $\mathrm{F}$ a $5 \%$ de significância.

No experimento 2, estimou-se o desempenho de frangos no período de 1 a 42 dias de idade alimentados com diferentes níveis de proteína na fase pré-inicial.

O delineamento utilizado foi em blocos casualizados (o lado do galpão foi o critério para escolha dos blocos), com cinco tratamentos $(18,20,22,24$ e $26 \%$ PB), cada um com seis repetições de 62 aves. Foram utilizados dois galpões de alvenaria divididos em 16 boxes de 2,10 x 2,50 m.

Foram alojados 1.860 pintos machos Ross com um dia de vida, em densidade de 12 aves $/ \mathrm{m}^{2}$, com campânulas a gás, dois comedouros tipo tubular infantil e dois bebedouros de pressão. Utilizou-se casca de arroz como cama, mantida de 8 a $10 \mathrm{~cm}$ de altura, e adotou-se um esquema de iluminação de três horas de escuridão por dia. 
O experimento constou de quatro fases de criação: préinicial (1 a 7 dias), inicial (8 a 21 dias), de crescimento (22 a 35 dias) e final ( 36 a 42 dias de idade). Na Tabela 1 constam a composição percentual dos ingredientes e o valor nutricional das rações pré-iniciais e, na Tabela 2, são apresentados os valores nutricionais das rações utilizadas nas fases de crescimento e final.

Foram medidos os pesos das aves, das rações fornecidas e as sobras no 1으, 끄, 14으, 21으, 35으 e 42으 dias de idade. Calculou-se ainda a mortalidade das aves, à medida que ocorria, efetuando-se o registro da data de ocorrência e do peso das aves ao longo do período experimental. Esses dados foram utilizados para o cálculo do ganho de peso dentro das fases e no período total, do consumo de ração e do índice de conversão alimentar corrigido pelo peso das aves mortas.

$\mathrm{O}$ índice de viabilidade da criação foi calculado pela subtração de 100 pelo valor de mortalidade encontrado e o índice de eficiência produtiva, pela fórmula IEP $=(($ ganho de peso $x$ viabilidade da criação)/(dias ate o final do experimento x conversão alimentar)) x 100.

Os dados foram analisados utilizando-se o programa SAEG (Sistema de Análises Estatísticas e Genéticas),

Tabela 2 - Composição e níveis nutricionais das rações experimentais utilizadas nas fases de crescimento e final (experimento 2) Table 2 - Composition and nutritional levels of growing and final diets (experiment 2)

\begin{tabular}{lrr}
\hline $\begin{array}{l}\text { Ingrediente } \\
\text { Ingredient }\end{array}$ & $\begin{array}{c}\text { Ração de crescimento (22 a 38 dias) } \\
\text { Growing diet (22 to 38 days) }\end{array}$ & $\begin{array}{r}\text { Ração final (39 a } \\
\text { Final diet (39 to }\end{array}$ \\
\hline Milho (Corn) & 64,888 & 65,468 \\
Farelo de soja (Soybean meal) & 31,595 & 29,748 \\
Fosfato bicálcico (Dicalcium phosphate) & 1,772 & 1,587 \\
Calcário calcítico (Limestone) & 0,909 & 0,982 \\
DL-Met 99 & 0,077 & 0,065 \\
Sal comum (Salt) & 0,266 & 0,257 \\
Premix inicial (Starter premix) & 0,400 & 0,400 \\
Óleo vegetal (Vegetable oil) & 0,094 & 1,493 \\
Total & 100,00 & 100,00
\end{tabular}

Nível nutricional

Nutritional level

\begin{tabular}{llr}
\hline PB $(\%)(C P, \%)$ & 18,20 & 17,450 \\
EMAn (kcal/kg) (EMAn, kcal/kg) & 2,950 & 3,050 \\
Gordura (\%) (Fat, \%) & 2,472 & 3,875 \\
Lisina (\%) (Lysine, \%) & 1,056 & 004 \\
Aminoácidos sulfurados (\%) (Sulphur amino acids, \%) & 0,727 \\
Metionina (\%) (Methionine, \%) & 0,392 \\
Treonina(\%) (Threonine, \%) & 0,783 \\
Triptofano(\%) (Thryptophan, \%) & 0,264 \\
Cálcio (\%) (Calcium, \%) & 0,885 \\
P disponível (\%) (Available P, \%) & 0,443 \\
Sódio (\%) (Sodium, \%) & 0,148
\end{tabular}

1 Suplemento vitamínico com aminoácidos e aditivos, níveis de garantia por quilograma de produto (broiler vitamin supplement, levels per kilogram): vit. A - 3.125 .000 UI; vit. D3 - 550.000 UI; vit. E - 3.750 mg; vit. K3 - 625 mg; vit. B1 - 250 mg; vit. B2 - 1.125 mg; vit. B6 - 250 mg; vit. B12 - 3.750 mcg; niacina (niacin) - $9.500 \mathrm{mg}$; pantotenato de cálcio (calcium pantotenate)- $750 \mathrm{mg}$; ácido fólico (folic acid)- $125 \mathrm{mg}$, DL-metionina (DL-methionine) - $350.000 \mathrm{mg}$; cloreto de colina $50 \%$ (choline chloride)- $150.000 \mathrm{mg}$; promotor de crescimento (growth promoter)- $12.500 \mathrm{mg}$; coccidiostático (anticoccidial agent)- $15.000 \mathrm{mg}$; Se - $50 \mathrm{mg}$; antioxidante (antioxidant) - $2.500 \mathrm{mg}$, veículo q.s.p. - $1.000 \mathrm{~g}$.

2 Suplemento mineral para aves, níveis de garantia por quilograma de produto (broiler mineral supplement, levels per kilogram): Mn - 150.000 mg; Zn - 100.000 mg; $\mathrm{Fe}-100.000 \mathrm{mg}$; Cu - $16.000 \mathrm{mg}$; I - $1.500 \mathrm{mg}$.

desenvolvido pela Universidade Federal de Viçosa (UFV, 1998), aplicando-se a análise de variância e, posteriormente, a regressão polinomial.

\section{Resultados e Discussão}

No experimento 1, não houve efeito significativo $(\mathrm{P}>0,05)$ da interação níveis de proteína da dieta pré-inicial $\times$ sexo das aves sobre as variáveis de desempenho. O ganho de peso médio dos pintos que receberam níveis crescentes de proteína na ração (Tabela 3 ) não diferiram $(\mathrm{P}>0,05)$ nos períodos de 1 a 7 e de 1 a 21 dias.

No período de 1 a 7 dias de idade, o ganho de peso nas fêmeas foi maior $(\mathrm{P}<0,05)$ que nos machos, provavelmente em virtude do maior peso inicial das fêmeas. No período total (1 a 21 dias), o ganho de peso dos machos foi superior $(\mathrm{P}<0,05)$, confirmando sua maior eficiência. Rocha et al. (2003) encontraram diferença para os níveis de PB (20, 23 e 
Tabela 3 - Desempenho de frangos de corte alimentados na fase pré-inicial (1 a 7 dias) com rações contendo diferentes níveis de PB Table 3 - Performance of broilers fed increasing dietary CP levels in the pre-starter period (1 to 7d)

\begin{tabular}{|c|c|c|c|c|c|c|}
\hline \multirow[t]{2}{*}{$\begin{array}{l}\text { Proteína } \\
\text { Protein }\end{array}$} & \multicolumn{2}{|c|}{$\begin{array}{c}\text { Ganho de peso }(\mathrm{g}) \\
\text { Weight gain }\end{array}$} & \multicolumn{2}{|c|}{$\begin{array}{l}\text { Consumo de ração }(\mathrm{g}) \\
\text { Feed intake }\end{array}$} & \multicolumn{2}{|c|}{$\begin{array}{l}\text { Conversão alimentar } \\
\text { Feed-to-gain ratio }\end{array}$} \\
\hline & $1-7$ & $1-21$ & $1-7$ & $1-21^{1}$ & $1-7$ & $1-21$ \\
\hline 20 & 89,2 & 607,9 & 94,91 & 866,73 & 1,096 & 1,489 \\
\hline 22 & 93,2 & 645,5 & 98,12 & 899,79 & 1,087 & 1,453 \\
\hline 24 & 96,5 & 630,8 & 104,98 & 895,95 & 1,094 & 1,453 \\
\hline \multicolumn{7}{|l|}{ Sexo } \\
\hline Macho (Male) & $89,5 b$ & $632,9 a$ & 96,22 & 879,51 & 1,089 & $1,444 \mathrm{~b}$ \\
\hline Fêmea (Female) & $94,7 \mathrm{a}$ & $611,8 b$ & 102,96 & 879,98 & 1,116 & $1,486 a$ \\
\hline $\mathrm{CV}(\%)^{2}$ & 7,5 & 3,5 & 11,31 & 3,22 & 8,85 & 3,28 \\
\hline
\end{tabular}

Para sexo, médias com letras minúsculas diferentes na mesma coluna diferem $(P<0,05)$ pelo teste $F$.

For sex, means with small letters within a collumn differ $(P<0.05)$ by Tukey test.

${ }^{1}$ Efeito quadrático (Quadratic effect)- $\hat{Y}=113,169+67,638 X-1,465 X-r^{2}=0,58$

${ }^{2} \mathrm{CV}=$ coeficiente de variação (CV = coefficient of variation).

26\%) na fase pré-inicial no período de 1 a 7 dias de idade, mas a diferença não foi constatada no período de 1 a 21 dias de idade.

O consumo de ração não foi afetado pelos níveis crescentes de proteína na ração nos períodos de 1 a 7 dias de idade (Tabela 3). No período total (1 a 21 dias), foi observado efeito quadrático $(\mathrm{P}<0,05)$, com ponto de máxima em 23,08\%. Stringhini (1998) verificou influência dos níveis protéicos $(20,22,24$ e $26 \%$ PB) sobre o consumo no período de 1 a 7 dias de idade, que foi maior para rações contendo $20 \%$ em comparação àquelas com $26 \%$ PB.

A conversão alimentar não foi afetada $(\mathrm{P}>0,05)$ pelo aumento do nível de proteína da ração, mas os machos apresentaram melhores índices $(\mathrm{P}<0,05)$ no período de 1 a 21 dias de idade (Tabela 3). No experimento realizado por Stringhini (1998), os menores níveis protéicos (20 e 22\% PB) resultaram em pior conversão alimentar no período de 1 a 7 dias de idade. O mesmo resultado foi observado por Rocha et al. (2003), que verificaram que o nível de $26 \%$ PB proporcionou melhores resultados de conversão alimentar no período de 1 a 7 dias $(1,170)$ se comparado ao de $20 \%$ PB (1,263). No período de 1 a 21 dias, no entanto, essas diferenças não existiram.

Não houve interação $(\mathrm{P}>0,05)$ balanço $\times$ retenção dos nutrientes. O balanço de MS (Tabela 4) não foi influenciado pelo aumento do nível de proteína (P>0,05). Andrade (2001) observou maior balanço de MS para $20,0 \%$ em comparação a 23,1 e 25,1\% PB. Rocha et al. (2003) encontraram diferença para balanço de MS e maior retenção de MS em rações com $20 \%$ (seguidas daquelas com 23 e $26 \%$ PB).

O balanço da proteína (Tabela 4) não foi influenciado pelo aumento do nível de proteína (P>0,05). Andrade (2001) verificou que o balanço de proteína foi menor em rações com $20 \%$ PB em comparação àquelas com 21,4; 23,1 e 25,1\% PB. Rocha et al. (2003), no entanto, não observaram efeito para balanço e retenção de proteína quando testaram níveis de 20, 23 e 26\% PB. O balanço e a retenção de EE apresentaram efeito linear positivo com o aumento do nível protéico da ração (Tabela 4).

Noy \& Sklan (1995) sugeriram que na primeira semana a proteólise não seria suficiente para a hidrólise das proteínas endógenas e exógenas, causando, assim, maior excreção fecal de nitrogênio. Com baixa digestão da proteína, ocorre interferência no balanço dos nutrientes. Os autores observaram que a digestão ileal de nitrogênio aumentou de 78 para $80 \%$ aos 4 e 7 dias de idade, chegando a $90 \%$ aos 21 dias de idade. Resultado semelhante foi constatado por Uni et al. (1995a) para a digestão intestinal de nitrogênio, que aumentou de $78 \%$ aos 4 dias para $90 \%$ aos 14 dias.

Penz \& Vieira (1998) verificaram que pintos de corte têm maior necessidade de proteína na primeira semana de vida, em decorrência da capacidade metabólica de termorregulação (pouco desenvolvida). O catabolismo dos aminoácidos em excesso causaria aumento no calor metabólico, beneficiando as aves neste período, o que, talvez, poderia explicar o aumento da retenção de proteína no organismo.

Avaliando a eficiência de retenção de proteína e gordura, Noy \& Sklan (2002) verificaram que níveis crescentes de proteína da dieta pré-inicial $(18,23$ e $28 \%$ PB) proporcionaram aumento na retenção de proteína e redução na retenção de gordura.

Aos 4 dias, a biometria dos órgãos digestivos e o comprimento do trato gastrintestinal não foram afetados ( $\mathrm{P}>0,05)$ pelos níveis protéicos testados (Tabela 5). 
Tabela 4 - Balanço (Bal) e retenção (Ret) de nutrientes das rações experimentais Table 4 - Nutrient balance (Bal) and retention index (Ret) of the experimental diets

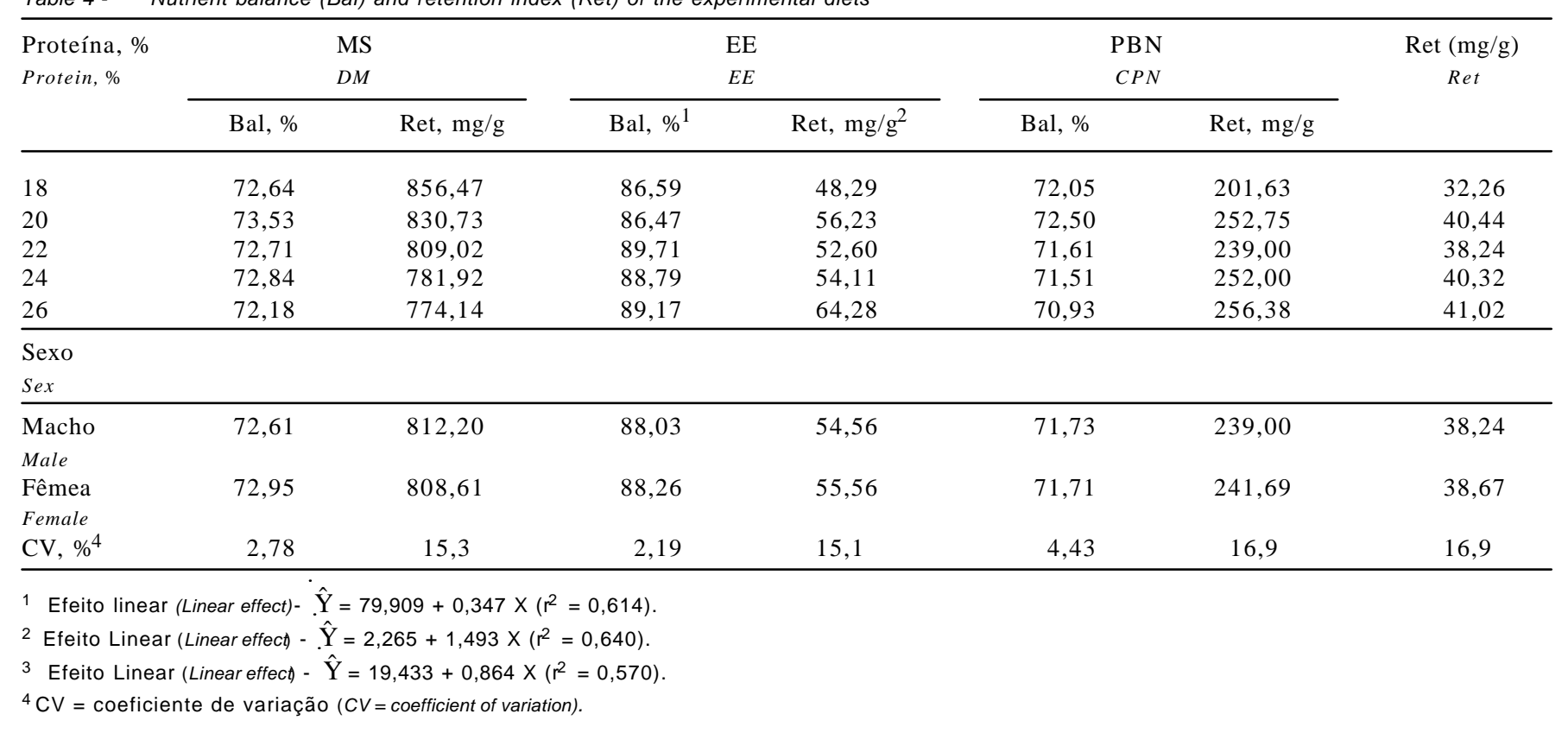

O peso relativo do pró-ventrículo + moela não foi influenciado pelos tratamentos aos $7 \mathrm{e}$ aos 14 dias de idade e apresentou efeito quadrático aos 10 dias de idade $(\mathrm{P}<0,05)$, com ponto de mínima de $23,28 \%$ PB. Com o aumento do nível de proteína da ração, o pâncreas apresentou crescimento linear $(\mathrm{P}<0,05)$ aos 7 dias e efeito quadrático aos 10 dias de idade, com ponto de mínima de $20,57 \%$ PB.

O efeito observado para pâncreas pode ter sido causado pelo maior estímulo do órgão com a presença de mais proteína na dieta. Nitsan et al. (1973) observaram maior peso do pâncreas com o aumento do nível protéico da dieta em gansos. Krogdahl (1985) relatou que o tamanho do pâncreas aumentou rapidamente durante a primeira semana, aumentando de $0,2 \%$ do peso corporal no primeiro dia para $0,5 \%$ aos 7 dias, como resultado da crescente produção de enzimas digestivas.

O comprimento do trato gastrintestinal mostrou efeito quadrático aos 7 dias de idade, com maior comprimento para $21,66 \%$ PB. Uni et al. (1995b) verificaram que o aumento no número de enterócitos por vilos e o volume dos vilos são expressivo no período pós-eclosão.

Em poucos estudos foram observados efeitos da dieta sobre o peso ou o desenvolvimento dos órgãos digestivos nesse período. Utilizando dietas pré-iniciais para pintos de corte com diferentes pesos ao primeiro dia (36,4 e 47,5 g), Stringhini et al. (2003) não verificaram diferenças para o peso relativo dos órgãos quando as aves receberam dieta pré-inicial até 4, 7 ou 10 dias de idade. Rocha et al. (2003), avaliando diferentes níveis protéicos $(20,23$ e 26\%) e energéticos (2.850 e 3.000 kcal) na dieta pré-inicial, também não detectaram diferenças significativas para peso relativo dos órgãos (fígado, intestinos, moela, coração).

Houve efeito da interação $(\mathrm{P}<0,05)$ nível protéico da ração $\times$ sexo apenas para peso relativo do fígado aos 14 dias e para peso relativo do intestino grosso aos 7 dias de idade. Pelo desdobramento da interação (Tabela 6), verificou-se, em machos, efeito linear positivo para peso relativo do intestino grosso aos 7 dias de idade à medida que o nível de proteína da dieta aumentou.

Andrade (2001) verificou maior peso relativo do fígado em aves alimentadas com $20 \%$ de PB e para aquelas que receberam rações com relação 100 Lys: $76 \mathrm{Met}+$ Cys. Noy \& Sklan (2002), por sua vez, não verificaram efeito do nível protéico sobre os pesos relativo e absoluto do fígado e do intestino delgado. Stringhini et al. (2002) encontraram dife renças no peso relativo do fígado aos 7 dias de idade, sem efeitos posteriores aos 21 dias de idade, porém, os maiores valores foram encontrados no nível de $22 \%$ PB.

Os dados obtidos no experimento 2 no período préinicial (Tabela 7), de 1 a 7 dias, não indicaram diferença estatística para o desempenho das aves. Stringhini (1998), trabalhando com diferentes níveis (20, 22, 24 e 26\% de PB) na fase pré-inicial, observou maior ganho de peso no tratamento com $22 \%$ de PB e maior consumo de ração, com pior conversão alimentar, no tratamento com $20 \%$ de PB. Rocha et al. (2003), avaliando rações com diferentes níveis de proteína, detectaram diferença no período préin icial para consumo, ganho de peso e conversão alimentar. 
Tabela 5 - Biometria dos órgãos digestivos de frangos de corte aos 4, 7, 10 e 14 dias alimentados com rações com diferentes níveis de proteína na fase pré-inicial ( 1 a 7 dias de idade)

Table 5 - Digestive organs biometry at 4, 7, 10 and 14 days of age for broilers fed increasing dietary CP levels in the pre-starter period (1 to 7 days)

\begin{tabular}{|c|c|c|c|c|c|c|}
\hline \multirow[t]{2}{*}{$\begin{array}{l}\text { Órgão } \\
\text { Organ }\end{array}$} & \multicolumn{5}{|c|}{$\begin{array}{c}\text { Nível de PB (\%) } \\
\text { CP level }(\%)\end{array}$} & \multirow[b]{2}{*}{$\mathrm{CV}(\%)$} \\
\hline & 18 & 20 & 22 & 24 & 26 & \\
\hline \multicolumn{7}{|l|}{4 dias de idade ( 4 days of age) } \\
\hline Fígado, \% (Liver, \%) & 4,43 & 4,45 & 4,15 & 4,23 & 4,62 & 13,74 \\
\hline Esôfago+papo, \% (Esophagus + crop, \%) & 1,66 & 1,53 & 1,63 & 1,77 & 1,83 & 18,04 \\
\hline Proventrículo+moela,\% (Proventiculus + gizzard, \%) & 10,98 & 12,11 & 11,07 & 10,59 & 11,52 & 11,86 \\
\hline Pâncreas, \% (Pancreas, \%) & 0,43 & 0,40 & 0,41 & 0,48 & 0,45 & 19,04 \\
\hline Intestino delgado, \% (Small intestine, \%) & 5,55 & 6,17 & 4,24 & 5,43 & 6,27 & 20,14 \\
\hline Intestino grosso, $\%$ (Large intestine, $\%$ ) & 1,93 & 2,05 & 1,93 & 1,84 & 2,11 & 21,31 \\
\hline Comprimento TGI, $\mathrm{cm}$ (GTI height, $\mathrm{cm})$ & 74,23 & 72,42 & 71,65 & 74,43 & 77,00 & 9,22 \\
\hline
\end{tabular}

7 dias de idade ( 7 days of age $)$

Fígado, \% (Liver, \%)

Esôfago+papo, \% (Esophagus+crop, \%)

\begin{tabular}{rrrrrr}
4,88 & 3,94 & 4,16 & 4,13 & 4,24 & 17,76 \\
1,12 & 1,57 & 0,93 & 1,25 & 1,35 & 17,56 \\
8,96 & 9,00 & 8,79 & 8,88 & 9,14 & 8,55 \\
0,42 & 0,43 & 0,46 & 0,49 & 0,52 & 16,09 \\
5,97 & 8,14 & 6,58 & 4,38 & 6,40 & 25,71 \\
92,87 & 98,50 & 100,37 & 95,02 & 91,87 & 7,30 \\
& & & & & \\
\hline
\end{tabular}

Proventriculo+moela, \% (Proventiculus+gizzard, \%)

Pâncreas, \% (Pancreas, \%)

Intestino delgado, \% (Small intestine, \%)

Intestino grosso, \% (Large intestine, \%)

Comprimento TGI, cm (GTI height, $\mathrm{cm})^{3}$

10 dias de idade (10 days of age)

Fígado, \% (Liver, \%)

$\begin{array}{lll}4,11 & 3,81 & 3,79\end{array}$

Esôfago+papo, \% (Esophagus+crop, \%)

Proventriculo+moela, \% (Proventiculus + gizzard, $\%)^{4}$

1,06

7,73

Pâncreas, \% (Pancreas, \%)

Intestino delgado, \% (Small intestine, \%)

Intestino grosso, \% (Large intestine, \%)

Comprimento TGI, cm (GTI height, $\mathrm{cm})$

5,78

1,87

111,37

\section{0,88}

6,98

0,44

14 dias de idade (14 days of age)

Fígado, \% (Liver, \%)

Esôfago+papo, \% (Esophagus +crop, \%)

Proventriculo+moela, \% (Proventiculus + gizzard, \%)

Pâncreas, \% (Pancreas, \%)

Intestino delgado, \% (Small intestine, \%)

Intestino grosso, \% (Large intestine, \%)

5,71

1,40

$\begin{array}{rrr}1,04 & 0,82 & 0,95 \\ 6,02 & 5,87 & 6,02 \\ 0,44 & 0,37 & 0,37 \\ 5,13 & 4,37 & 4,92 \\ 1,22 & 1,37 & 1,23 \\ 119,67 & 120,37 & 117,12\end{array}$

3,79
1,05
7,26
0,42
5,89
1,36
12,32

\section{3,39}

1,81

6,26

0,44

5,79

1,62

112,67

\begin{tabular}{rr}
3,91 & 12,34 \\
1,22 & 55,86 \\
7,17 & 5,83 \\
0,55 & 9,92 \\
5,75 & 11,70 \\
1,59 & 12,47 \\
111,15 & 4,38 \\
\hline
\end{tabular}

12,34

5,83

9,92

1,70
2,47

4,38

${ }^{1}$ Os dados percentuais correspondem ao peso relativo do órgão em relação ao peso vivo da ave (Percentual data corresponds to organ weight relative to body weight).

2 Efeito linear para peso relativo pâncreas aos sete dias (Linear effect on pancreas relative weight at seven days) $-\hat{Y}=0,186+0,0127 . X\left(R^{2}=0,989\right)$

3 Efeito quadrático para comprimento do trato gastrointestinal aos sete dias (Quadratic effect on gastrointestinal length at seven days) $-\hat{\mathrm{Y}}=-106,395+19,021 \mathrm{X}-$ $0,439 \times X^{2}\left(R^{2}=0,878\right)$.

${ }^{4}$ Efeito quadrático para peso relativo do pró-ventrículo + moela aos 10 dias (Quadratic effect on proventriculus + gizzard at seven days) $\hat{\mathrm{Y}}=26,687-1,718 \mathrm{X}+0,0369$ $X^{2}\left(R^{2}=0,550\right)$.

${ }^{5}$ Efeito quadrático para peso relativo do pâncreas aos 10 dias (Quadratic effect on pancreas relative weight at ten days) $\hat{Y}=2,288-0,181 X+0,00439 X^{2}\left(R{ }^{2}=0,864\right)$.

6 Efeito quadrático para peso relativo do esôfago + papo aos 14 dias (Quadratic effect on esophagus + crop relative weight at 14 days) $-\hat{\mathrm{Y}}=6,077-0,476 \mathrm{X}+0,0108$ $X^{2}\left(R^{2}=0,578\right)$.

Andrade (2001), no entanto, não encontrou diferença estatística no desempenho dos frangos de corte neste mesmo período.

Na fase inicial, de 1 a 21 dias de vida, o desempenho dos frangos (Tabela 8) não foi afetado pelos níveis de proteína testados $(\mathrm{P}>0,05)$. Houve efeito linear sobre a viabilidade econômica da criação $(\mathrm{P}<0,05)$.

Nascimento et al. (1998) encontraram diferença estatística somente no consumo de ração. Rocha et al. (2003), no entanto, não notaram diferença no desempenho no período de 1 a 21 dias em aves recebendo 20, 23 e 26\% PB na ração. Leandro et al. (2003), trabalhando com diferentes densidades nutricionais $(20,45 ; 20,50 ; 21,00$ e $21,50 \%$ de PB e 2.990, 3.020, 3.050 e 3.080 kcal de EM), não encontraram diferença no ganho de peso e no consumo de ração para a fase inicial (1 a 21 dias de idade). Andrade (2001), trabalhando com diferentes relações energia:proteína $(115-2.900 \mathrm{kcal} / \mathrm{kg}$ EM e $25,1 \% \mathrm{~PB}, 125-2.900 \mathrm{kcal} / \mathrm{kg}$ EM e $23,1 \%$ PB, $135-2.900 \mathrm{kcal} / \mathrm{kg}$ EM e 21,4\% PB e 145 - $2.900 \mathrm{kcal} / \mathrm{kg}$ EM e 20,0\% PB) também não encontrou diferença estatística para a fase inicial ( 1 a 21 dias de idade). 
Tabela 6 - Desdobramento da interação nível protéico de ração $\times$ sexo para peso relativo do fígado e do intestino grosso de frangos de corte alimentados com rações contendo diferentes níveis de proteína na fase préinicial

Table 6 - Development of dietary $C P$ levels $\times$ sex interaction for liver relative weight and large intestine for broilers fed increasing dietary $\mathrm{CP}$ levels in the pre-starter period

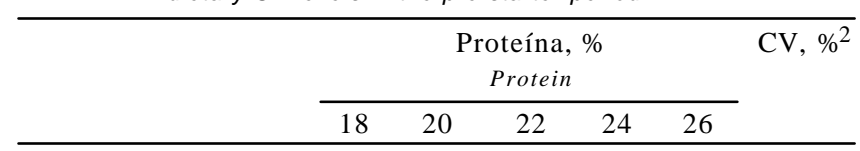

Fígado aos 14 dias

Liver at 14 days of age

\begin{tabular}{lllllll}
\hline Macho (male) & 3,48 & 3,12 & 2,97 & 3,00 & 3,38 & 9,81 \\
Fêmea (female) & 3,10 & 3,07 & 3,53 & 3,75 & 3,03 & 6,76 \\
\hline
\end{tabular}

Intestino grosso aos 7 dias

Large intestine at seven days of age

\begin{tabular}{|c|c|c|c|c|c|c|}
\hline Macho (male $)^{1}$ & 1,56 & 1,58 & 1,80 & 1,87 & 2,11 & 6,04 \\
\hline Fêmea (female) & 1,31 & 2,86 & 1,95 & 2,07 & 2,22 & 12,18 \\
\hline
\end{tabular}

${ }^{1}$ Efeito linear (linear effect) - $\hat{Y}=0,252+0,6467 \times\left(R^{2}=0,942\right)$.

$2 \mathrm{CV}=$ coeficiente de variação (coefficient of variation).

Tabela 7 - Desempenho de frangos no período de 1 a 7 dias de idade alimentados com rações contendo diferentes níveis de proteína na fase pré-inicial (experimento 2)

Table 7 - Performance of broilers from 1 to 7 days of age fed increasing dietary $\mathrm{CP}$ levels in the pre-starter period (experiment 2)

\begin{tabular}{lcccc}
\hline $\begin{array}{l}\text { Proteína } \\
(\%)\end{array}$ & $\begin{array}{c}\text { Ganho de } \\
\text { peso }(\mathrm{g}) \\
\text { Peight gain }\end{array}$ & $\begin{array}{c}\text { Consumo de } \\
\text { ração }(\mathrm{g}) \\
\text { Feed }\end{array}$ & $\begin{array}{c}\text { Convertake } \\
\text { alimentar }\end{array}$ & $\begin{array}{c}\text { Feed-to-gain ratio } \\
\text { Feiabilidade } \\
(\%)\end{array}$ \\
\hline 18 & 72,68 & 101,40 & 1,447 & 93,39 \\
20 & 97,88 & 114,44 & 1,170 & 98,15 \\
22 & 85,87 & 11,84 & 1,307 & 96,30 \\
24 & 89,11 & 106,19 & 1,194 & 96,56 \\
26 & 83,17 & 107,56 & 1,321 & 97,35 \\
\hline
\end{tabular}

Tabela 8 - Desempenho de frangos no período de 1 a 21 dias de idade alimentados com rações contendo diferentes níveis de proteína na fase pré-inicial (experimento 2)

Table 8 - Performance of broilers from 1 to 21 days of age fed increasing dietary CP levels in the pre-starter period (experiment 2)

\begin{tabular}{lcccc}
\hline $\begin{array}{l}\text { Proteína } \\
(\%)\end{array}$ & $\begin{array}{c}\text { Ganho de } \\
\text { peso }(\mathrm{g}) \\
\text { Weight gain }\end{array}$ & $\begin{array}{c}\text { Consumo de } \\
\text { ração }(\mathrm{g}) \\
\text { Feed intake }\end{array}$ & $\begin{array}{c}\text { Conversão } \\
\text { alimentar }\end{array}$ & $\begin{array}{c}\text { Veed-to-gain ratio }^{\text {Vilidade }} \\
(\%)\end{array}$ \\
\hline 18 & 548,99 & 808,50 & 1,474 & 78,84 \\
20 & 678,50 & 989,63 & 1,462 & 96,56 \\
22 & 669,93 & 965,12 & 1,441 & 95,77 \\
24 & 683,08 & 964,15 & 1,412 & 95,50 \\
26 & 664,35 & 902,00 & 1,480 & 96,03 \\
\hline 1 Efeito linear (linear effect) $-\hat{Y}=44,55154+1,783853 X-\mathrm{R}^{2}=0,8600$
\end{tabular}

No período total (Tabela 9), não houve diferença $(\mathrm{P}>0,05)$ para as variáveis de desempenho avaliadas e não se constatou efeito dos níveis de proteína na ração pré-inicial.

Stringhini (1998) não encontrou diferença para conversão alimentar quando utilizou quatro níveis de proteína na ração inicial (20, 22, 24 26\%). Stringhini et al. (2002) também não observaram melhora no desempenho de aves alimentadas com rações contendo níveis crescentes de proteína (20 a $25 \%)$ na fase pré-inicial. Leandro et al. (2003), avaliando densidades nutricionais em programas alimentares para frangos de corte, também não encontraram diferença neste período.

\section{Conclusões}

Níveis mais altos de proteína na fase pré-inicial propiciaram resultados de desempenho e retenção de nutrientes mais adequados em pintos de corte.

Tabela 9 - Desempenho de frangos no período de 1 a 42 dias de idade alimentados com rações com diferentes níveis de proteína na fase pré-inicial (experimento 2)

Table 9 - Performance of broilers from 1 to 42 days of age fed increasing dietary CP levels in the pre-starter period (experiment 2)

\begin{tabular}{lccccc}
\hline $\begin{array}{l}\text { Proteína (\%) } \\
\text { Protein }\end{array}$ & $\begin{array}{c}\text { Ganho de peso }(\mathrm{g}) \\
\text { Weight gain }\end{array}$ & $\begin{array}{c}\text { Consumo de ração }(\mathrm{g}) \\
\text { Feed intake }\end{array}$ & $\begin{array}{c}\text { Conversão alimentar } \\
\text { Feed-to-gain ratio }\end{array}$ & $\begin{array}{c}\text { Viabilidade (\%) } \\
\text { Viability }\end{array}$ & $\begin{array}{c}\text { Índice de eficiência produtiva } \\
\text { Productive efficiency index }\end{array}$ \\
\hline 18 & 1,900 & 3,877 & 2,048 & 79 & 1,745 \\
20 & 2,144 & 3,916 & 1,833 & 93 & 2,590 \\
22 & 2,200 & 3,886 & 1,759 & 92 & 2,740 \\
24 & 2,246 & 3,855 & 1,723 & 92 & 2,855 \\
26 & 2,166 & 3,896 & 1,799 & 91 & 2,609 \\
\hline
\end{tabular}




\section{Agradecimento}

Ao CNPq e ao Abatedouro São Salvador (Itaberaí, GO), pelo apoio técnico-financeiro à realização dos experimentos.

\section{Literatura Citada}

ALBINO, L.F.T.; ROSTAGNO, H.S.; TAFURI, M.L. Determinação dos valores de energia metabolizável aparente e verdadeira de alguns alimentos para aves, usando diferentes métodos. Revista da Sociedade Brasileira de Zootecnia, v.21, n.6, p.10471058, 1992.

ANDRADE M.L. Efeito da relação energia: proteína e aminoácidos sulfurados:lisina na ração pré-inicial sobre o desempenho de frangos de corte. Goiânia: Universidade Federal de Goiás, 2001. 33p. Monografia (Especialização em Zootecnia) - Universidade Federal de Goiás, 2001.

BARANYIOVÁ, E.; HOLMAN, J. Morphological changes in the intestinal wall in fed and fasted chickens in the first week after hatching. Acta Veterinaria Brno, v.45, p.151-158, 1976.

CAFÉ, M.B.; SAKOMURA, N.K.; JUNQUEIRA, O.M. et al. [2000] Determination of the nutritional values of processed full-fat soybeans for poultry. Revista Brasileira de Ciência Avícola [online], v.2, n.1, p.67-74, 2000. Disponível em: <http:// www.scielo.br/scielo.php?script $=$ sci_arttext \&pid $=$ S1516$635 X 2000000100009 \& \operatorname{lng}=e n \& n r m=i s o>$. Acesso em: 20/06/06.

DESCHEPPER, K.; DE GROOTE, G. Effect of dietary protein, essential and non-essential amino acids on the performance and carcass composition of male broiler chickens. British Poultry Science, v.36, n.3, p.229-245, 1995.

DIBNER, J. Nutritional requirements of young poultry. In: MEETING OF ARKANSAS NUTRITION CONFERENCE, 1996, Fayetteville. Proceedings... Fayetteville: Arkansas Poultry Federation, 1996. p.15-27.

FREITAS, B.C.F.; BAIÃO, N.C.; NUNES, I.J. et al. Digestibilidad de la grasa en las primeras semanas de vida del pollo de carne. In: CONGRESSO LATINO AMERICANO DE AVICULTURA, 16., 1999, Lima. Anais... Lima: Latinoamericana de Avicultura, 1999. p.356-359.

GONZALES, E.; SALDANHA, E.S.P.B. Os primeiros dias de vida do frango e a produtividade futura. In CONGRESSO BRASILEIRO DE ZOOTECNIA, 11., CONGRESSO INTERNACIONAL DE ZOOTECNIA, 3., 2001, Goiânia. Anais... Goiânia: Universidade Católica de Goiás, 2001. p.310-327.

GONZALES, E.; LEANDRO, N.S.M.; VAROLI JR., J.C. et al. O tempo de jejum do neonato e a restrição alimentar quantitativa influenciando a produtividade de frango de corte na idade de abate. Revista Brasileira de Ciência Avícola, supl.2. p.4, 2000.

HOLSHEIMER, J.P.; JANSSEN, W.M.M.A. Limiting amino acids in low protein maize-soyabean meal diets fed to broiler chicks from 3 to 7 weeks of age. British Poultry Science, v.32, n.1, p.151-158, 1991

KROGDAHL, A. Digestion and absorption of lipids in poultry. Journal of Nutrition, v.115, p.675-685, 1985.

LEANDRO, N.S.M.; CAFÉ, M.B.; STRINGHINI, J.H. et al. Plano nutricional com diferentes níveis de proteína bruta e energia metabolizável na ração, para frangos de corte. Revista Brasileira de Zootecnia, v.32, n.3, p.620-631, 2003.

MAIORKA, A. Efeitos da idade da matriz e do agente trófico (glutamina) sobre o desenvolvimento da mucosa intestinal e atividade enzimática do pâncreas de pintos de corte na primeira semana. Jaboticabal: Universidade Estadual Paulista, 2002. 100p. Tese (Doutorado em Zootecnia), Universidade Estadual Paulista, 2002.

MATTERSON, L.D.; POTTER, L.M.; STUTZ, M.W. et al. The metabolizable energy of feeds ingredients for chickens. Storrs: The University of Connecticut, Agricultural Experiment Station, 1965. 11p. (Research Report).
MORAN JR., E.T. Digestion and absorption of carbohydrates in fowl and events through perinatal development. Journal of Nutrition, v.115, n.2, p.665-671, 1985

NASCIMENTO, A.H.; ALBINO, L.F.T.; POZZA, P.C. et al. Energia e relação energia:proteína na fase inicial de frangos de corte. In: CONFERÊNCIA APINCO DE CIÊNCIA E TECNOLOGIA AVÍCOLAS, 1998, Campinas. Trabalhos de Pesquisa... Campinas: Fundação Apinco de Ciência e Tecnologia Avícolas, 1998. p.15.

NITSAN, Z.; NIR, I.; DROR, Y. et al. The effect of forced feeding and of dietary protein level on enzymes associated with digestion, protein and carbohydrate metabolism in geese. Poultry Science, v.52, n.2, p.474-481, 1973.

NOY, Y.; SKLAN, D. Digestion and absorption in the young chick. Poultry Science, v.74, p.366-373, 1995.

NOY, Y.; SKLAN, D. Nutrient use in chicks during the first week posthatch. Poultry Science, v.81, p.391-399, 2002.

PARR, J.F.; SUMMERS, J.D. The effect of minimizing amino acid excesses in broiler diets. Poultry Science, v.70, n.7, p.15401549, 1991.

PENZ JR., A.M.; VIEIRA, S.L. Nutrição na primeira semana. In: CONFERÊNCIA APINCO DE CIÊNCIA E TECNOLOGIA AVÍCOLAS, 1998, Campinas. Anais... Campinas: Fundação Apinco de Ciência e Tecnologia Avícolas, 1998. p.121-139.

ROCHA, P.T.; STRINGHINI, J.H.; ANDRADE, M.A. et al. Desempenho de frangos de corte alimentados com rações préiniciais contendo diferentes níveis de proteína bruta e energia metabolizável. Revista Brasileira de Zootecnia, v.32, n.1, p.162-170, 2003.

ROSTAGNO, H.S.; ALBINO, L.F.T.; DONZELE, J.L. et al.Tabelas Brasileiras para aves e suínos (composição de alimentos e exigências nutricionais). Viçosa, MG: Universidade Federal de Viçosa, 2000. 141p.

SILVA, D.J. Análise de alimentos (métodos químicos e biológicos). 2.ed. Viçosa, MG: Universidade Federal de Viçosa, 1990. 165p.

SKLAN, D. Development of the digestive tract of poultry. World's Poultry Science Journal, v.57, n.4, p.415-428, 2001.

SKLAN, D.; NOY, Y. Hidrolysis and absortion in the small intestines of posthatch chicks. Poultry Science, v.79, p.1306-1310, 2000.

STRINGHINI, J.H. Níveis de proteína e aminoácidos em rações para frangos de corte criados em duas densidades populacionais. Jaboticabal: Universidade Estadual Paulista, 1998. 123p. Tese (Doutorado em Zootecnia) - Universidade Estadual Paulista, 1998.

STRINGHINI, J.H.; ANDRADE, M.L.; ROSA, R.M. et al. Nível de proteína e balanço de aminoácidos essenciais da ração pré-inicial (1 a 7 dias) de pintos de corte. Ciência Animal Brasileira, v.3, n.1, p.21-30, 2002.

STRINGHINI, J.H.; RESENDE, A.; CAFÉ, M.B. et al. Efeito do peso inicial dos pintos e do período da dieta pré-inicial sobre o desempenho de frangos de corte. Revista Brasileira de Zootecnia, v.32, n.2, p.353-360, 2003.

UNI, Z.; GANOT, S.; SKLAN, D. Posthatch development of mucosal function in the broiler small intestine.Poultry Science, v.77, p.75-82, 1998

UNI, Z.; NOY, Y.; SKLAN, D. Development of the small intestine in heavy and light strain chicks before and after hatching. British Poultry Science, v.36, p.63-71, 1995a.

UNI, Z.; NOY, Y.; SKLAN, D. Posthatch changes in morphology and function of the small intestines in heavy- and light- strain chicks. Poultry Science, v.74, p.1622-1629, 1995b.

UNI, Z.; NOY, Y.; SKLAN, D. Posthatch development of small intestinal function in the poultry. Poultry Science, v.78, n.1, p.215-222, 1999.

ZIGGERS, D. Controlando las ganancias mediante el nivel proteico de la dieta. Industria Avícola, v.20, n.2, p.11-13, 2002.

Recebido: $17 / 11 / 04$

Aprovado: 21/06/06 